\title{
POLÍTICAS PÚBLICAS, AGROECOLOGIA E AGROEXTRATIVISMO NOS ASSENTAMENTOS RURAIS DO MUNICÍPIO DE CÁCERES, REGIÃO SUDOESTE MATO-GROSSENSE
}

\section{PUBLIC POLICIES, AGROECOLOGY AND AGROEXTRACTIVISM IN THE RURAL SETTLEMENTS THE CITY OF CÁCERES, REGION SOUTHWEST MATO GROSSO}

\author{
Maurício Ferreira Mendes ${ }^{1}$, Sandra Mara Alves da Silva Neves ${ }^{2}$, Ronaldo José Neves ${ }^{2}$ \\ ${ }^{1}$ Universidade Federal de Goiás (UFG), Goiânia, GO, Brasil \\ ${ }^{2}$ Universidade do Estado de Mato Grosso (UNEMAT), Cáceres, MT, Brasil
}

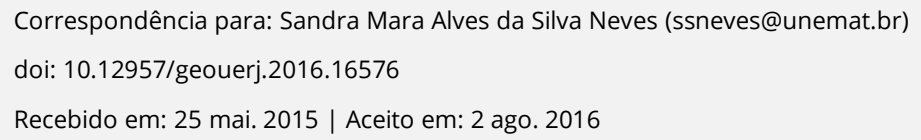

\section{RESUMO}

O texto objetivou-se discutir como as políticas públicas, a agroecologia e o agroextrativismo contribuem para a segurança alimentar e nutricional das famílias camponesas do município de Cáceres/MT, além de destacar a importância destes instrumentos na apropriação e fortalecimento dos camponeses frente à chegada da cana-deaçúcar, expropriação de terras e a pressão dos grandes latifundiários em torno dos assentamentos do município. Os procedimentos metodológicos adotados foram: pesquisa bibliográfica, visando subsidiar teoricamente as análises efetuadas; coleta de dados e informações nos órgãos públicos; além de trabalho de campo. As experiências concretas em agroecologia do município de Cáceres contribuem diretamente para o bem-estar das famílias camponesas, gerando renda e segurança alimentar e nutricional, uma vez que são produzidos alimentos de qualidade e em quantidade suficiente para o sustento familiar e comercializado os excedentes. $O$ sucesso deste modelo está na relação harmoniosa com a natureza, ao contrário do modelo de desenvolvimento dominante no Brasil que se apoia sobre um modo de produção que necessita cada vez mais destruir os recursos naturais, de consumir mais produtos, contaminando o ambiente com os defensivos agrícolas utilizados na produção da agricultura convencional.

Palavras-chave: Agricultura familiar camponesa. Políticas públicas. Segurança alimentar e nutricional. Geração de renda. Mato Grosso.

\begin{abstract}
The paper aimed to discuss how public policies, agroecology and agroextractivism contribute to food and nutritional security of rural families in the municipality of Cáceres/MT, in addition to highlighting the importance of these instruments on ownership and empowerment of the peasants against the arrival of cane sugar, land grabs and the pressure of the big landowners around the settlements of the municipality. The methodological procedures were adopted: literature review, aiming theoretically subsidize their analyzes; collecting data and information on public bodies; addition to field work. Concrete experiences in agroecology the city of Cáceres directly contribute to the welfare of rural families, generating income and food security and nutrition, since they are produced food of sufficient quality for family sustenance and marketed surplus amount. The success of this model is in harmonious relationship with nature, unlike the dominant development model in Brazil that relies on a mode of production that requires increasingly destroy natural resources, consume more products, contaminating the environment with pesticides used in the production of conventional agriculture.
\end{abstract}

Keywords: Peasant family agriculture. Public policy. Food and nutrition security. Income generation. Mato Grosso.

\section{INTRODUÇÃO}


No Brasil, o tema políticas públicas para a agricultura familiar camponesa, a agroecologia e o agroextrativismo tem ganhado relevância nos últimos anos, devido principalmente à luta dos movimentos sociais e a recriação do Conselho Nacional de Segurança Alimentar e Nutricional (CONSEA), pelo Governo Federal, em 2003. "Esse fórum permanente de debate, elaboração e articulação das diferentes ações, programas e políticas de segurança alimentar e nutricional permitiu qualificar a atuação do Estado, bem como as pautas de negociação dos movimentos sociais com o governo" (PORTO, 2008, p. 4).

O Programa de Aquisição de Alimentos (PAA), o Programa Nacional de Alimentação Escolar (PNAE) têm sido instrumentos importantes para orientar a ação do Estado nesse campo (PORTO, 2008). 0 PAA e o PNAE surgiram apresentando um referencial de política identificado com o enfoque da segurança alimentar e nutricional. Ademais, foi importante neste processo a criação do Ministério do Desenvolvimento Agrário (MDA) em 1999 e a Secretaria de Extrativismo e Desenvolvimento Rural Sustentável em 2003 do Ministério do Meio Ambiente (MMA).

No Brasil, 31,3 milhões de pessoas (16,7\%) habitam áreas rurais e a maioria das propriedades (58\%) são menores que 25 hectares, incluindo agricultores camponeses, assentados, povos e comunidades tradicionais, que têm como meio de vida a agricultura camponesa e a exploração de produtos da biodiversidade para o consumo e renda; daí a importância de replicar experiências exitosas que acessaram a política para que outras populações também acessem, contribuindo para a segurança alimentar e nutricional e mitigação da pobreza no campo (SCARIOT, 2011). Neste sentido, o Governo Federal vem implementando um conjunto de políticas que estão diretamente relacionadas à estratégia de fornecer segurança alimentar e nutricional e renda as pessoas excluídas, como os camponeses, os quilombolas, extrativistas, etc. Em particular, um dos instrumentos para isso é o PAA, que é um programa governamental que procura contribuir diretamente com o aumento da renda para os agricultores de pequenas unidades do campo, ou seja, a agricultura camponesa, ao mesmo tempo em que visa o combate à fome e a miséria (BRASIL, 2013). 
Outro fator que pode contribuir para minimização da insegurança alimentar no campo é a agroecologia e o agroextrativismo. Nesse contexto, Caporal (2009, p. 16-17) afirma:

A agroecologia, além de tratar sobre o manejo ecologicamente responsável dos recursos naturais, constitui-se em um campo do conhecimento científico que, partindo de um enfoque holístico e de uma abordagem sistêmica, pretende contribuir para que as sociedades possam redirecionar o curso alterado da coevolução social e ecológica, nas suas mais diferentes interrelações e mútua influência, conservando os recursos naturais e gerando alimentos diversificados e sem produtos químicos.

Segundo Altieri (1989) esses desafios são enormes complexos, visto que a natureza impõe limitações e, para superá-los, é necessário um profundo conhecimento sobre o ambiente, englobando aspectos físicos, químicos e biológicos. "É necessária uma nova agricultura que concilie processos biológicos (base do crescimento de plantas e animais) e processos geoquímicos e físicos (base do funcionamento de solos que sustentam a produção agrícola) com os processos produtivos e os sociais" (ALTIERI, 1989, p. 42).

Assim, o agroextrativismo tem uma longa história no Brasil, pois a utilização dos elementos da flora e da fauna de áreas de florestas nativas têm sido um meio fundamental de subsistência para os povos da Amazônia e do Cerrado nos últimos 6 a 8 mil anos (DRUMMOND, 1996). Apresenta como uma alternativa econômica para diversas comunidades e assentamentos rurais que utilizam a biodiversidade do Cerrado para a promoção da segurança alimentar e geração de renda, como vem acontecendo em estados brasileiros, como Mato Grosso, Mato Grosso do Sul, Goiás, Tocantins e Minas Gerais.

Diante do exposto, objetivou-se discutir como as políticas públicas (PAA e PNAE), a agroecologia e o agroextrativismo contribuem para a segurança alimentar e nutricional das famílias camponesas do município de Cáceres/MT, além de destacar a importância destes instrumentos na apropriação e fortalecimento dos camponeses no município. 
Os procedimentos metodológicos adotados foram: pesquisa bibliográfica, visando subsidiar teoricamente as análises efetuadas; coleta de dados secundários em órgãos públicos, como o Instituto Nacional de Colonização e Reforma Agrária (INCRA) e o Sindicato dos Trabalhadores e Trabalhadoras Rurais de Cáceres (STTR-CAC), que buscaram resgatar informações do processo de articulação e organização das experiências agroecológicas e extrativistas dos camponeses no município de Cáceres, região Sudoeste Mato-grossense.

\section{Os assentamentos rurais de Cáceres, região sudoeste mato-grossense}

A colonização do município de Cáceres/MT teve início no século XVIII a partir do garimpo e da exploração da poaia (Psychotria ipecacuanha), uma planta nativa do Mato Grosso, possuidora de propriedades medicinais. Por volta de 1732, o ouro de aluvião em Cuiabá apresentava sinais de esgotamento e a busca de novas áreas conduziu os exploradores ao vale do rio Guaporé, região Sudoeste do estado (MATO GROSSO, 2008).

Em 1778, foi fundada Cáceres, devido à fertilidade do solo e das abundantes águas; pela necessidade de defesa e incremento da fronteira Sudoeste de Mato Grosso; e por ser elo da comunicação entre Vila Bela da Santíssima Trindade (Capital do Estado na época) e Cuiabá e dessas cidades com São Paulo (CHAVES, 2011). Desde logo, a economia cacerense e da região estruturou-se em torno de atividades agropecuárias (criação de gado bovino e culturas como mandioca, abóbora, arroz e feijão) e do extrativismo animal e vegetal, o que possibilitou o desenvolvimento de Cáceres e, consequentemente, a sua elevação de vila a município.

O município de Cáceres está situado na porção Sudoeste do Estado (Figura 1). Possui uma população de 87.942 habitantes, distribuída nos seus 24.351,408 Km2 de extensão territorial (IBGE, 2015). A sede municipal, situada à margem esquerda do Rio Paraguai, dista $215 \mathrm{Km}$ da capital do Estado (Cuiabá) e totaliza 68,95 Km2 (COCHEV et al., 2010). 
O município possui $57,08 \%$ de área inserida no Pantanal Mato-grossense e o restante da área territorial na Província Serrana e na Depressão do Rio Paraguai, recobertos principalmente por vegetação de Cerrado. O clima de Cáceres é tropical estacional, com duas estações definidas, uma chuvosa, de novembro a abril, e outra seca, de maio a setembro. A temperatura média anual do município é de $26,24^{\circ} \mathrm{C}$ (NEVES et al., 2011).

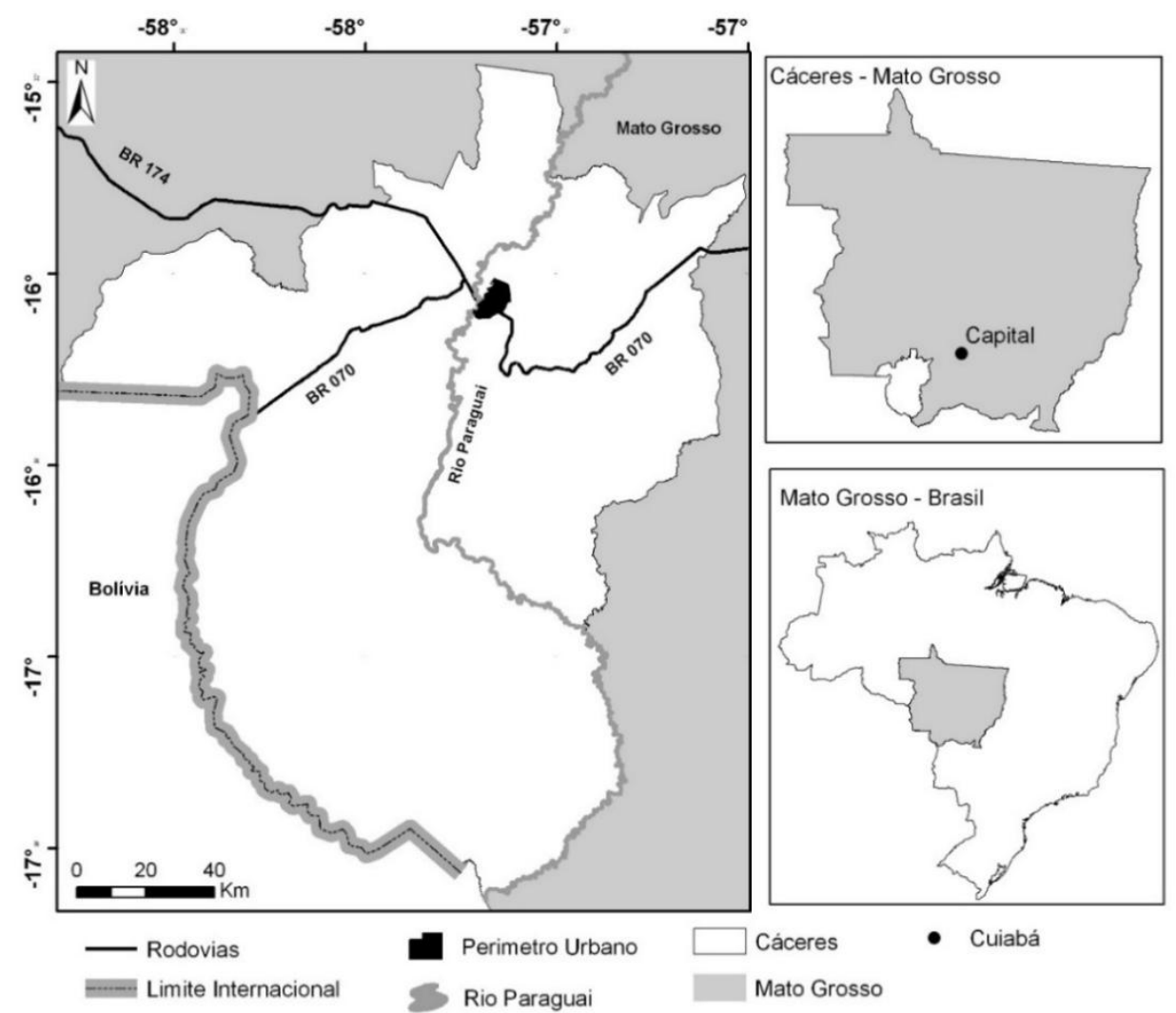

Figura 1. Localização do município de Cáceres, região Sudoeste Mato-grossense, Brasil. Fonte: SILVA, M. A. (2013).

O Índice de Desenvolvimento Humano (IDH) de 2010 do município de Cáceres foi de 0,708, inferior ao IDH do estado de Mato Grosso $(0,725)$ e do País $(0,744)$. As dimensões apresentadas foram as seguintes: renda (0,691), longevidade $(0,813)$ e educação $(0,633)$ (PNUD, 2013). O melhor desempenho de Cáceres foi na dimensão de longevidade, as dimensões de renda e educação apresentaram índices baixos, devido ao município ofertar pouca oportunidade de trabalho e renda para a população, além disso, serão necessários maiores investimentos na educação. 
No município de Cáceres, predomina a pecuária, ou seja, criação de gado para corte e leite em extensas áreas de terra, coexistindo com inúmeros assentamentos, comunidades tradicionais, camponeses e etnias indígenas, como os chiquitanos. Os 18 assentamentos do município de Cáceres (Tabela 1), apresentam 1.607 famílias assentadas, e está em fase de implantação pelo Instituto Nacional de Colonização de Reforma Agrária (INCRA) mais um assentamento: Flechas.

Os assentamentos de Cáceres são precários, com pouca infraestrutura, não havendo sequer postos de saúde. Além disso, os camponeses se deparam com várias dificuldades, como falta de água, sementes, assistência técnica e crédito (MENDES, 2013).

Com referência à organização das famílias camponesas, deve-se fazer uma menção especial às associações e grupos informais existentes no território e cabe destacar que o associativismo e o cooperativismo vêm ganhando força nos últimos anos. Esse fenômeno estimulou os camponeses a reativar diversas associações e criar novas, garantindo assim a comercialização dos produtos da agricultura familiar via políticas públicas.

\begin{tabular}{|c|c|c|c|}
\hline Município & $\begin{array}{l}\text { Quantidade de } \\
\text { assentamentos } \\
\end{array}$ & $\begin{array}{c}\text { Nome do } \\
\text { assentamento }\end{array}$ & $\begin{array}{c}\text { Quantidade de } \\
\text { famílias assentadas }\end{array}$ \\
\hline \multirow{18}{*}{ Cáceres } & \multirow{18}{*}{18} & Barranqueira & 77 \\
\hline & & Bom sucesso & 14 \\
\hline & & Corixo & 74 \\
\hline & & Facão/Bom jardim & 169 \\
\hline & & Flor da Mata & 22 \\
\hline & & Ipê Roxo & 28 \\
\hline & & Jatobá & 27 \\
\hline & & Katira & 46 \\
\hline & & Laranjeira I & 126 \\
\hline & & Laranjeira II & 33 \\
\hline & & Limoeiro & 166 \\
\hline & & Nova Esperança & 48 \\
\hline & & Paiol & 221 \\
\hline & & Rancho da Saudade & 47 \\
\hline & & Sadia Vale Verde & 423 \\
\hline & & São Luiz & 27 \\
\hline & & Sapicuá & 39 \\
\hline & & Recompensa II & 20 \\
\hline
\end{tabular}


Tabela 1. Número de famílias assentadas por assentamento rural do município de Cáceres, região Sudoeste Mato-grossense. Fonte: Instituto de Colonização de Reforma Agrária (INCRA-MT/2015).

Oliveira et al. (2013) mostraram que a maioria das famílias dos assentamentos de Cáceres são oriundas de Mato Grosso (95,7\%); que o tamanho dos lotes varia de 4,5 a 45 hectares; quanto a experiência com a terra, 91,3\% declararam possuir alguma experiência com a agricultura e pecuária antes de morar nestes assentamentos, fato que contribui para a diversificação das unidades produtivas dos camponeses. Dos 18 assentamentos, sete estão situados na faixa de fronteira Brasil - Bolívia e não possuem água potável para consumo e muito menos para os animais, como o gado bovino; a solução é buscar água em uma mina a $10 \mathrm{~km}$ do assentamento.

Outros dados importantes dos assentamentos de Cáceres mostram que as escolas dos assentamentos estão fechando, como exemplo, a Escola Municipal Professora Vera Ligia Baldo, no assentamento Facão/Bom Jardim que foi fechada em 2010. Na região da fronteira Brasil - Bolívia, a única unidade escolar que está em funcionamento é a Escola Municipal Nossa Senhora de Aparecida, do assentamento Sapicuá.

O retrato do município de Cáceres não é diferente do apresentado no restante dos outros municípios brasileiros, em que no meio rural concentra o maior número de pobres e o Brasil segue ostentando um dos piores índices de desigualdade social do mundo; a continuidade desse panorama num país com vastas disponibilidades territoriais, ambientais e econômicas e culturais só pode ser explicada pela permanência do histórico padrão de desenvolvimento que reproduz estruturas de poder bloqueadoras de acesso das populações empobrecidas aos seus benefícios (ROMANO, 2008).

As políticas e os programas governamentais para o campo têm sido incapazes de desarticular essas estruturas, uma vez que são concebidas para promover a plena cidadania e a inserção dos mais pobres nas dinâmicas de desenvolvimento econômico. Ao contrário, orientam-se a partir da falsa dicotomia que considera parte do universo das famílias rurais como agentes econômicos, enquanto a outra parte, a mais pobre, é vista como beneficiária da assistência social. Além disso, a tese de que a superação da pobreza será alcançada por meio do crescimento turbinado pelo agronegócio continua a legitimar politicamente o modelo de desenvolvimento rural concentrador 
de renda e dos fatores de produção, sobretudo a terra. A essência perversa dessa concentração se manifesta na patente contradição entre índices empregados na medida do desenvolvimento: enquanto o Produto Interno Bruto (PIB) do agronegócio apresenta crescimento vertiginoso no curto prazo, o Índice de Desenvolvimento Humano (IDH) nos territórios de expansão das monoculturas permanece baixo ou mesmo em queda. (ROMANO, 2008, p. 2).

Mesmo enfrentando dificuldades, os camponeses de Cáceres realizam diversas experiências agroecológicas, agroextrativistas, e de acesso a políticas públicas, como o PAA e o PNAE, abordado no próximo item deste texto.

\section{As políticas públicas, a agroecologia e o agroextrativismo nos assentamentos rurais de Cáceres}

Dos 18 assentamentos do município de Cáceres dez possuem associações (Quadro 1), que são importantes por possibilitarem aos camponeses o acesso as políticas públicas, mais especificamente o PAA e o PNAE.

Somente a partir da luta e mobilização do coletivo dos camponeses nos assentamentos de Cáceres e a união das forças é possível buscar soluções para os desafios enfrentados localmente e regionalmente relativos às atividades produtivas, tais como: comercialização dos produtos da agricultura familiar camponesa, registros e documentos para firmar contratos, entre outros. Nesse contexto, as associações em geral do município têm como objetivo e fins congregar as famílias de camponeses para a promoção econômica, social e a proteção ambiental.

\begin{tabular}{|cccccc|}
\hline Assentamento & Associações & $\begin{array}{c}\text { Experiências } \\
\text { Agroecológicas }\end{array}$ & $\begin{array}{c}\text { Experiências } \\
\text { Agroextrativistas }\end{array}$ & $\begin{array}{c}\text { Grupo de } \\
\text { Mulheres }\end{array}$ & $\begin{array}{c}\text { Acesso ao } \\
\text { PAA* } \\
\text { PNAE** }\end{array}$ \\
\hline Barranqueira & & & & & \\
Bom sucesso & & $\mathrm{X}$ & $\mathrm{X}$ & $\mathrm{X}$ & $\mathrm{X}$ \\
Corixo & $\mathrm{X}$ & $\mathrm{X}$ & $\mathrm{X}$ & $\mathrm{X}$ & $\mathrm{X}$ \\
Facão/Bom & $\mathrm{X}$ & & & & \\
Jardim & & & & & \\
Flor da Mata & & & &
\end{tabular}




\begin{tabular}{|ccccc|} 
Jatobá & $\mathrm{X}$ & & & \\
Katira & $\mathrm{X}$ & & & \\
Laranjeira I & $\mathrm{X}$ & & & \\
Laranjeira II & $\mathrm{X}$ & & & \\
Limoeiro & & & $\mathrm{X}$ & \\
Nova Esperança & $\mathrm{X}$ & & & $\mathrm{X}$ \\
Paiol & $\mathrm{X}$ & $\mathrm{X}$ & $\mathrm{X}$ & \\
Rancho da & $\mathrm{X}$ & & & \\
Saudade & & & & \\
Sadia Vale Verde & $\mathrm{X}$ & & & \\
São Luiz & $\mathrm{X}$ & & & \\
Sapicuá & & & & \\
Recompensa II & & & & \\
\hline
\end{tabular}

Quadro 1. Associações, experiências agroecológicas, agroextrativistas, grupo de mulheres e acesso a políticas públicas (PAA e PNAE) nos assentamentos rurais de Cáceres, região Sudoeste Mato-grossense.

* Programa de Aquisição de Alimentos (PAA). ** Programa Nacional de Alimentação Escoar (PNAE). Fonte: Sindicato dos Trabalhadores e Trabalhadoras Rurais de Cáceres (STTR Cáceres/2015).

O Facão/Bom Jardim é um dos poucos assentamentos estruturados de Cáceres; os camponeses estão organizados na Associação de Pequenos Produtores Familiares Flor de Ipê, composta por 45 famílias associadas, que têm como carro chefe a produção de hortaliças agroecológicas (Figura 2), além da produção de cereais, frutas, farinhas, queijos e criação de pequenos animais para o consumo próprio das famílias e para a venda via mercado institucional (Quadro 1).

Segundo Almeida e Schmitt (2009), a diversificação da produção é um elemento fundamental do ponto de vista da sustentabilidade dos ecossistemas. A interação funcional entre policultivos e criações, em diversificadas combinações inter e intra-espécies, pode proporcionar a maior otimização e resiliência dos agroecossistemas, propiciando assim, segurança alimentar da própria família e potencializando sua capacidade de fornecer alimentos para o mercado em diferentes épocas do ano.

Os agricultores familiares também contam com experiências agroecológicas no assentamento Corixo e Sadia Vale Verde, onde trabalham via associação produzindo hortaliças agroecológicas. 

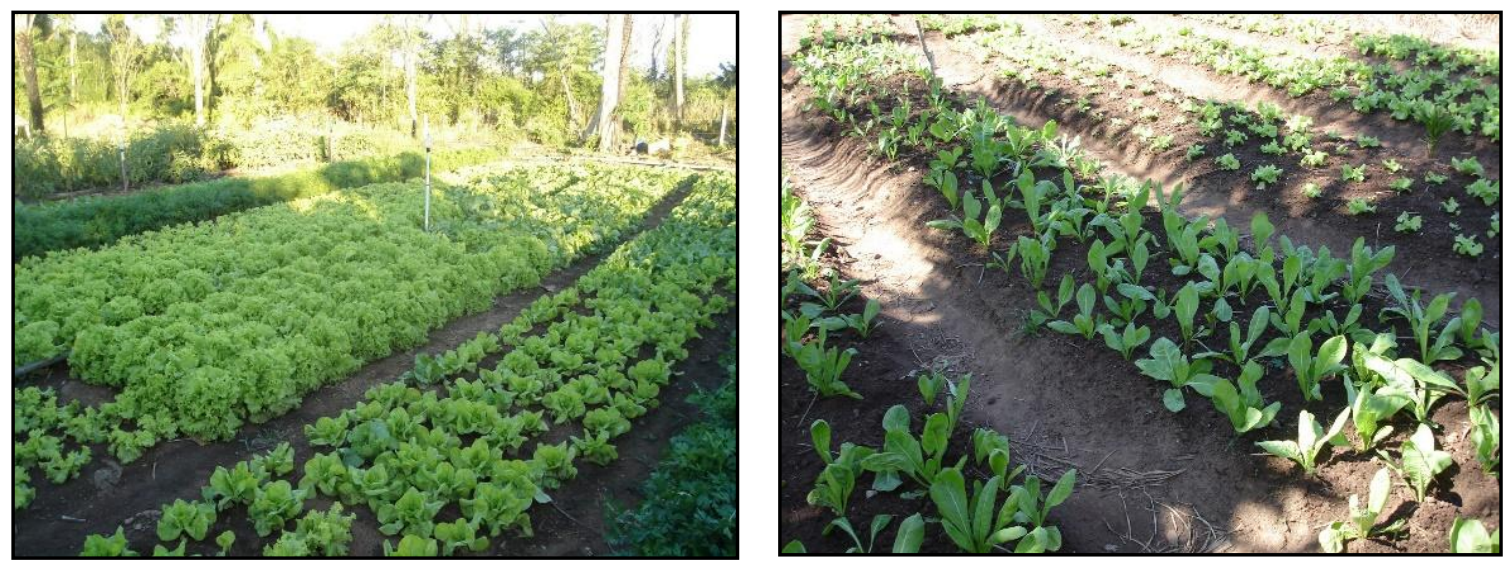

Figura 2. Produção de hortaliças com práticas agroecológicas no assentamento Facão/Bom Jardim, município de Cáceres/MT. Fonte: MENDES, M. F. (2015).

No assentamento Corixo, além da produção agroecológica de hortaliças, há uma Associação Regional de Produtoras Extrativistas do Pantanal (ARPEP), que foi originada a partir de um grupo de mulheres que iniciou suas atividades em 2005, culminando em 2009 na criação da associação. Com o intuito de buscar soluções conjuntas para os principais desafios: comercialização dos frutos nativos, registros e documentos para firmar contratos, redução de custos, empoderamento e protagonismo das mulheres (Quadro 1).

Atualmente a ARPEP possui 108 agricultoras associadas, distribuídas em três unidades de processamento de frutos nativos, sendo duas situadas no município de Cáceres e uma em Mirassol D’Oeste. Administra um fundo rotativo solidário, executa projetos de comercialização, via PAA/Conab e Programa Nacional de Alimentação Escolar (PNAE), fazendo valer a Lei nº 11.947/2009 que determina no mínimo 30\% da aquisição de alimentos da Agricultura Familiar (MENDES, 2013).

As duas unidades situadas em Cáceres são a Unidade de Processamento São José (UPSJ), localizada no assentamento Bom Jardim/Furna São José, que começou a funcionar no ano de 2011, tendo o cumbaru (Dipteryx alata) como principal produto e a Unidade de Processamento Corixo (UPC0), situada no assentamento Corixo, que iniciou suas atividades também em 2011, tendo o pequi (Caryocar brasiliense) como principal fruto para comercialização (MENDES et al., 2013). 
Por fim, vale destacar a experiência agroextrativista realizada no assentamento Sadia Vale Verde, cujas atoras sociais organizadas na Associação de Mulheres Agricultoras Familiares Araras do Pantanal - AMAFAP, elaboram produtos derivados do cumbaru, que são comercializados via PAA e o PNAE (Quadro 1). A AMAFAP foi criada em 2006 para fortalecer a participação das mulheres nas atividades produtivas da unidade familiar e para ter um espaço de encontros e debates.

Todas as experiências agroextrativistas dos assentamentos Corixo, Facão/Bom Jardim e Sadia (Quadro 1) utilizam diversos frutos nativos na alimentação como o buriti (Mauritia flexuosa), jatobá do Cerrado (Hymenaea stigonocarpa), mangava (Hancornia speciosa) entre outros, esses frutos associados a produção de feijão, abóbora, milho e hortaliças promove a segurança alimentar e nutricional, pois os frutos do Cerrado possuem diversos nutrientes importantes para a população.

Além de debater as desigualdades (econômica e de poder) e relações de gênero, as mulheres que não conheciam e não utilizavam os frutos do Cerrado, os incorporaram em sua alimentação, através da produção de doces, geleias, cereais, mingaus, pães, bolos, paçoquinhas, sorvetes e licores. Surgindo assim novas possibilidades para a geração de renda e trabalho.

Além dos produtos derivados do extrativismo, a AMAFAP nos últimos anos tem investido na produção de hortaliças agroecológicas para o autoconsumo e o fornecimento do excedente da produção para duas escolas, uma no Sadia Vale Verde e outra no Paiol, contribuindo para a diversificação da alimentação dos alunos do ensino fundamental e médio (Quadro 1).

Segundo Pacheco (2008) todas essas experiências têm como tema mobilizador e articulador a soberania e segurança alimentar, o que ressalta o papel histórico que cumprem os camponeses nesse campo, uma vez que eles são levados a enfrentar os mais diversos contextos em que se manifesta a insegurança alimentar: falta de alternativas alimentares; potencial extrativista ameaçado, provocando a degradação ambiental; avanço da monocultura; expansão da pecuária; impactos das mudanças climáticas na produção agrícola; acesso as políticas públicas e a crise do sistema agroalimentar no plano internacional. 
A atual discussão sobre segurança alimentar no Brasil engloba fatores políticos e práticas sociais diversificadas que se desenvolvem a partir da complexidade da nossa realidade social, política, econômica e cultural. A questão tem ganho grande projeção política nos últimos tempos por referenciar ações de diversos movimentos sociais e sujeitos políticos da sociedade civil ligados ao meio urbano e rural. Ao analisarmos como esses movimentos sociais, redes e articulações nacionais traduzem, em ações práticas e políticas o conceito de segurança alimentar, torna-se evidente que as questões de gênero, mais precisamente aquelas ligadas às mulheres camponesas, adquirem grande realce nesse debate. (JALIL, 2009, p. 9).

Segundo o Sindicato dos Trabalhadores e Trabalhadoras Rurais (STTR-CAC), que assessora as famílias assentadas, existem aquelas em constante situação de insegurança alimentar nos assentamentos do município, ou seja, não possuem alimentos diversificados e em quantidade suficiente para sua alimentação. Essa lógica corrobora com a interpretação de Miranda (2009, p. 53) ao afirmar que "a simples disponibilização de acesso amplo a alimentos de baixo valor nutritivo, impõe um padrão alimentar precário e monótono, revelando a presença de uma base produtiva geradora de insegurança alimentar".

A definição de segurança alimentar estabelece que todas as pessoas devem ter acesso a alimentos em quantidades suficientes e de boa qualidade todos os dias, fomenta a autonomia da comunidade ao permitir que os camponeses decidam quais sementes plantar, que tipo de agricultura praticar, considerando as consequências locais dos processos políticos e econômicos em nível macro (PIMBERT, 2009).

Para assegurar a segurança alimentar é elementar investir no fortalecimento da agricultura camponesa, da comunidade tradicional, quilombolas e indígenas, como estratégia de descentralização do poder econômico, político e de garantia da segurança alimentar da humanidade.

O PAA e PNAE são políticas públicas estratégicas para a garantia de segurança alimentar e nutricional dos camponeses. É por esta razão que o Fórum Brasileiro de Segurança Alimentar e Nutricional (FBSAN) coloca os programas como eixos centrais da pauta nacional. O PNAE constitui 
parte integrante do projeto pedagógico da educação pública e, portanto, sua operacionalização é um dever do poder público e o PAA como parte integrante de uma política pública efetiva de comercialização para os camponeses (FBSAN, 2009).

Passados quase 70 anos desde que Josué de Castro publicou a obra "Geografia da Fome" (1946), a fome continua a ser um problema no Brasil, apesar dos avanços implementados através das políticas públicas. O autor questionou o latifúndio, associando o regime da fome à estrutura agrária do Brasil que concentra grandes extensões de terras em mãos de poucos, defendendo a reforma agrária que até hoje não foi efetivada no País.

A agroecologia não deve ser entendida como simplesmente um jeito de cultivar a terra ou como a utilização de técnicas que não agridam o ambiente. E sim como um paradigma científico que agrupa várias áreas do conhecimento, com intuito de perceber, estudar e interferir em processos sociais, políticos, organizativos, culturais, ecológicos e ambientais (ALTIERI, 1989).

Enquanto que a agroecologia influencia diretamente nos processos de mudanças de postura, de visão de futuro para o mundo e de atitude para com a natureza, assim como em relação ao ser humano. Enfim, é ter compreensão de que a esta contrapõe-se em essência ao modelo capitalista de desenvolvimento (ANA, 2007).

Toda essa discussão em torno de novas formas de relacionar com a natureza, adotando uma organização social e produtiva, não predatória dos elementos naturais estão sendo estimulados e paulatinamente incorporados pelos camponeses nos assentamentos rurais de Cáceres, a exemplo do Corixo, Facão/Bom Jardim, Katira, Sadia Vale Verde e Sapicuá (Quadro 1).

Os desafios são imensos, uma vez que mais camponeses são sujeitos a ficar dependentes de insumos externos e das tecnologias desenvolvidas pelas empresas multinacionais. A "Revolução Verde" alterou profundamente a agricultura no plano tecnológico, baseado no tripé: maquinários, defensivos agrícolas e sementes modificadas geneticamente. Esse modelo aliado à concentração urbana e à massificação da 
mídia, modificou o padrão de consumo, hoje quatro grãos: milho, arroz, soja e trigo concentram quase a totalidade de consumo de grãos no mundo, ou seja, está se perdendo a diversidade genética dos cultivares do planeta (CAPORAL, 2009).

A produção sem agrotóxicos é possível, a exemplo da produzida no assentamento Facão/Bom Jardim em que 45 famílias produzem hortaliças sem a utilização de defensivos agrícolas, popularmente denominado como veneno, ao invés utilizam caldas naturais e biofertilizantes. Experiências concretas de agroecologia contribuem diretamente para o bem-estar das famílias camponesas, gerando renda e segurança alimentar e nutricional. 0 sucesso deste modelo está na relação harmoniosa com a natureza, ao contrário do modelo de produção dominante no Brasil.

A agricultura camponesa é responsável pela produção dos principais alimentos consumidos pela população brasileira: $84 \%$ da mandioca, $67 \%$ do feijão, $54 \%$ do leite, $49 \%$ do milho, $40 \%$ das aves e ovos e 58\% dos suínos (NEAD, 2011). O exposto corrobora com a argumentação de Buainain et al. (2003) de que a agricultura camponesa é chave para o desenvolvimento do Brasil, no que tange a produção de alimentos e distribuição de renda.

\section{CONSIDERAÇÕES FINAIS}

As experiências agroecológicas dos camponeses contribuem diretamente para segurança alimentar e nutricional, pois as famílias produzem alimentos agroecológicos em quantidade e qualidade para o sustento das famílias e comercialização do excedente para o mercado institucional e em feiras na cidade, além de participações em eventos da agricultura camponesa. Porém, ainda são poucos os assentamentos de Cáceres que adotam a agroecologia para diversificar a produção.

Outro fator que contribui para a segurança alimentar são as experiências agroextrativistas dos assentamentos que manejam e realizam aproveitamento de frutos do Cerrado, os frutos contribuem na dieta alimentar, pois apresentam nutrientes e vitaminas, por exemplo, o buriti e o pequi têm alta concentração de betacaroteno que se transforma em vitamina A no organismo humano, o jatobá é rico 
em cálcio que é importante para o fortalecimento de dente e ossos, portanto os frutos do Cerrado representam um banco de nutrientes para a população da zona rural.

Constata-se ainda que nos últimos anos, as políticas públicas se tornaram instrumentos importantes dos camponeses frente a pressão dos latifundiários, garantindo a permanência na terra. Por fim, conclui-se que o sucesso deste modelo que utiliza a agroecologia e o agroextrativismo está na relação harmoniosa com a natureza e no associativismo realizado pelos camponeses. Nesse sentido, as políticas públicas de desenvolvimento rural são fundamentais para fomentar e fortalecer as iniciativas de produção e renda dos camponeses, contribuindo para a soberania alimentar e nutricional.

\section{REFERÊNCIAS}

ALMEIDA, Paula; SCHMITT, Claudia Job. Agrobiodiversidade para segurança alimentar: fortalecendo os direitos dos agricultores e agricultoras. Proposta, Rio de Janeiro, v. 33, n. 119, p. 28-35, nov. 2009.

ALTIERI, Miguel. Agroecologia: as bases científicas da agricultura alternativa. Rio de Janeiro: PTA/FASE, 1989. 240p.

ANA. Articulação Nacional de Agroecologia. Construção do conhecimento agroecológico. Rio de Janeiro: ANA/FASE, 2007. 283p.

BRASIL. Ministério do Desenvolvimento Social. Programa de Aquisição de Alimentos. 2013. Disponível em: http://www.mds.gov.br/segurancaalimentar/decom/paa. Acesso em: 02 ago. 2014.

BUAINAIN, Antônio Márcio; ROMEIRO, Ademar Ribeiro; GUANZIROLLI, Carlos. Agricultura familiar e o novo mundo rural. Sociologias, Porto Alegre, v. 5, n. 10, p. 312-347, jul./dez., 2003.

CAPORAL, Francisco Roberto. Agroecologia: uma nova ciência para apoiar a transição a agriculturas mais sustentáveis. In: CAPORAL, Francisco Roberto; PAULUS, Gervásio; COSTABEBER, José Antônio. (Org.). Agroecologia: uma ciência do campo da complexidade. Brasília/DF: dos autores, 2009. p. 9-64.

CASTRO, Josué de. Geografia da fome: o dilema brasileiro: pão ou aço. 10 ed. Rio de Janeiro: Antares, 1946, 361p.

COCHEV, Jakeline dos Santos; NEVES, Ronaldo José; NEVES, Sandra Mara Alves da Silva Neves. Espaço urbano de Cáceres/MT analisado a partir de imagens de sensoriamento remoto e SIG. Revista GeoPantanal, Corumbá/MS, v. 5, n. 8, p. 145-160, jan./jul., 2010.

DRUMMOND, José Augusto. A extração sustentável de produtos florestais na Amazônia Brasileira: vantagens, obstáculos e perspectivas. Estudos Sociedade e Agricultura, Rio de Janeiro, v. 1, n. 6, p. 115-137, jul., 1996.

FBSAN. Fórum Brasileiro de Segurança Alimentar e Nutricional. A terceirização da comida. Proposta, Rio de Janeiro, v. 33, n. 119 , p. 57-61, 2009.

IBGE. Cidades. Síntese de Cáceres/Mato Grosso.2010. Disponível em:

http://www.ibge.gov.br/cidadesat/topwindow.htm?1. Acesso em: 30 jul. 2014. 
JALIL, Laeticia. Soberania alimentar, feminismo e ação política: um olhar sobre as ações do movimento de mulheres camponesas. Agriculturas, Rio de Janeiro, v. 6, n. 4, p. 9-11, dez., 2009.

MATO Grosso. Plano de Desenvolvimento do Estado de Mato Grosso - MT + 20. Cuiabá: Secretaria de Planejamento do Estado de Mato Grosso, 2008. 342p.

MENDES, Maurício Ferreira et al. Riquezas nativas e agricultura familiar: a experiência da ARPEP na região sudoeste de Mato Grosso. Cadernos de Agroecologia, Porto Alegre, v. 8, n. 2, p. 1-5, 2013.

MIRANDA, Regina da Silva. Segurança e soberania alimentar: alimento ou mercadoria? Proposta, Rio de Janeiro, v. 33, n. 119, p. 50-55, nov., 2009.

NEAD. Núcleo de Estudos Agrários e Desenvolvimento Rural. O desafio do desenvolvimento agrário, 2011. Disponível em: http://www.nead.gov.br/portal/nead/.Acesso em: 04 ago. 2014.

NEVES, Sandra Mara Alves da Silva; NUNES, Maria Cândida Murtinho; NEVES, Ronaldo José. Caracterização das condições climáticas de Cáceres/MT Brasil, no período de 1971 a 2009: subsídios às atividades agropecuárias e turísticas municipais. B. Goiano. Geogr., Goiânia, v. 31, n. 2, p. 55-68, jul./dez., 2011.

OLIVEIRA, Renata Karla Pinto et al. Agricultura familiar em assentamentos rurais no município de Cáceres/MT: uma leitura socioeconômica. Cadernos de Agroecologia, Porto Alegre, v. 8, n. 2, p. 1-5, 2013.

PACHECO, Maria Emília Lisboa. O caminho das mudanças na construção da Agroecologia pelas mulheres. Agriculturas, Rio de Janeiro, v. 6, n. 4, p. 4-8, dez., 2008.

PIMBERT, Michel. Mulheres e soberania alimentar. Agriculturas, Rio de Janeiro, v. 6, n. 4, p. 4-8, dez., 2009.

PNUD. Programa das Nações Unidas para o Desenvolvimento. Atlas de Desenvolvimento Humano Brasil, 2013. Disponível em: http://www.pnud.org.br/idh/. Acesso em: 02 ago. 2014.

PORTO, Silvio Isopo. Acesso a mercados: desafios e oportunidades. Agriculturas, Rio de Janeiro, v. 5, n. 2, p. 4-6, jul., 2008.

ROMANO, Jorge. Pobreza: o problema e a construção de soluções. Agriculturas, Rio de Janeiro, v. 5, n. 4, p. 4-7, dez., 2008.

SCARIOT, Aldicir. Manejo de plantas do Cerrado: subsídios técnicos às políticas públicas de uso sustentável de uso e conservação da biodiversidade. Brasília/DF: Embrapa Cenargen, 2011. 39p.

SILVA, Marcela de Almeida et al. Avaliação da infraestrutura dos empreendimentos rurais de Cáceres/MT, para fins turísticos. Enciclopédia Biosfera, v. 9, n. 16, p. 2570-2582, 2013. 